\title{
EVALUACIÓN DE DOS PRUEBAS DE INMUNOBLOT CON ANTÍGENO HIDATÍDICO DE CAPRINO Y OVINO PARA EL DIAGNÓSTICO DE EQUINOCOCOSIS HUMANA
}

\author{
Eduardo Miranda ${ }^{1, a}$, Franko Velarde ${ }^{1, a}$, José Somocurcio ${ }^{2, b}$, Eduardo Ayala ${ }^{1, a}$
}

\begin{abstract}
RESUMEN
Para estimar el valor diagnóstico del antígeno hidatídico de caprino y de ovino en la prueba de inmunoblot para echinococosis quística, se usó 135 sueros, de los cuales 70 procedían de pacientes con hidatidosis confirmada por el hallazgo de protoescólices y membrana en el estudio anatomopatológico con la pieza quirúrgica; 45 a pacientes con otras enfermedades parasitarias y 20 a personas aparentemente sanas. La sensibilidad, la especificidad, el valor predictivo positivo y negativo de la prueba de inmunoblot, con antígeno hidatídico de caprino fue de 92,8\%, 100\%, 100\% y $92,8 \%$, respectivamente; mientras que de ovino fueron $91,4 \%, 95,3 \%, 95,5 \%$ y $91,1 \%$, respectivamente. El índice kappa fue de 0,93 para el antígeno caprino y de 0,86 con el ovino en relación con el estudio anatomopatológico. Se recomienda el uso de ambos antígenos para el diagnóstico serológico de la equinococosis quística humana.
\end{abstract}

Palabras clave: Equinococosis; Western blotting; Sensibilidad y especificidad; Reactividad cruzada (fuente: DeCS BIREME).

\section{EVALUATION OF TWO IMMUNOBLOT TESTS WITH GOAT AND SHEEP HYDATID ANTIGEN FOR HUMAN ECHINOCOCCOSIS DIAGNOSIS}

\begin{abstract}
To estimate the diagnosis value of goat and ovine antigen for echinococcosis immunoblot test, 135 serums were used, of which 70 were coming from patients with hydatid disease confirmed by the finding of proto scolex and membrane in the pathology study of surgical piece, 45 from patients with other parasitic diseases and 20 apparently healthy people. The sensitivity, the specificity, positive and negative predictive value of immunoblot test, with hidatyd antigen of goat was of $92.8 \%, 100 \%, 100 \%, 92.8 \%$, respectively, than for ovine antigen was $91.4 \%, 95.3 \%, 95.5 \%, 91.1 \%$, respectively. Kappa index was 0.93 for goat antigen and 0.86 with sheep in relation to the pathological study. We recommended the use of both antigens for the serologic diagnosis of human echinococcosis.
\end{abstract}

Key words: Echinococcosis; Blotting, western; Sensitivity and specificity; Cross-priming (source: MeSH NLM).

\section{INTRODUCCIÓN}

La equinococosis quística, zoonosis causada por el estadio larval del Echinococcus granulosus, es una enfermedad endémica en muchos países ganaderos del mundo y son muy pocas las naciones que han logrado erradicarla, dentro de los cuales podemos mencionar a Nueva Zelanda, Tasmania e Islandia. La equinococosis quística en Sudamérica tiene gran prevalencia en países como Argentina, Brasil, Uruguay, Chile y Perú (1). La prevalencia de echinococosis quística en el Perú, en los últimos siete años, oscila de 7-11/100 000 habitantes, sin embargo, hay departamentos con una alta prevalencia (con 14-34/100000 habitantes), tal es el caso de Pasco, Huancavelica, Arequipa, Junín, Lima, Puno, Cusco, Ayacucho, Ica y Tacna, zonas donde se cría ganado ovino y bovino; esta situación ocasiona altos costos hospitalarios con unas cifras que van entre 1000 y 5500 dólares por paciente ${ }^{(2,3)}$.

Para realizar las pruebas serológicas en el diagnóstico de la hidatidosis se usa como fuente de antígenos, el líquido hidatídico, los extractos de protoescólices y los de membranas envolventes, dando mejores resultados el uso del líquido, por contener macromoléculas secretoras y excretoras de la larva, que permiten detectar anticuerpos circulantes en el suero de pacientes con esta parasitosis ${ }^{(4)}$.

La prueba de inmunoblot es la más fiable cuando se realiza el diagnóstico serológico en laboratorio, pues es útil en la identificación de anticuerpos originados frente a antígenos complejos y cuyo principio es similar a la téc-

\footnotetext{
Centro Nacional de Salud Pública, Instituto Nacional de Salud. Lima, Perú.

2 Hospital Edgardo Rebagliati Martins, EsSalud. Lima, Perú.

Biólogo; ' Médico Anatomopatólogo.
}

Recibido: 07-01-10 Aprobado: 12-05-10 
nica de ELISA. Una vez separados los diferentes componentes antigénicos proteicos de una mezcla compleja por medio de una electroforesis en fase sólida en un gel de poliacrilamida, son transferidas a una membrana de nitrocelulosa en donde se situarán separadamente. Al entrar en contacto cada uno de los diferentes anticuerpos con el suero problema, este reaccionará inmunológicamente con su antígeno correspondiente formándose tantas bandas como reacciones antígeno / anticuerpo haya tenido lugar. Esta acción se pone en evidencia añadiéndose una antiinmunoglobulina marcada con una enzima. Finalmente, la adición de un sustrato incoloro da lugar a bandas coloreadas ${ }^{(5)}$.

Según Sánchez et al. ${ }^{(5,6)}$ y Gómez ${ }^{(7)}$, la técnica de inmunoblot utilizando antígeno de líquido hidatídico de ovino presenta una sensibilidad entre 88 y $95 \%$ y una especificidad entre 95 y $100 \%$. Por otro lado, Verástegui et al. ${ }^{(8)}$ evaluaron el inmunoblot usando antígeno de líquido hidatídico de vacuno obteniendo una sensibilidad de 80 y una especificidad del $100 \%$. Sin embargo, el criterio de especificidad para la interpretación de los resultados varía con relación a la procedencia del tipo de antígeno utilizado, es decir el antígeno de líquido hidatídico de ovino difiere al antígeno de líquido hidatídico de vacuno, en su contenido proteico antigénico ${ }^{(6-8)}$.

Al no existir estudios que hayan evaluado la técnica de inmunoblot con antígeno de líquido hidatídico de caprino y con el propósito de obtener un antígeno ideal para que los médicos logren un diagnóstico definitivo y certero en la población parasitada, es que en el presente estudio se planteó estimar el valor diagnóstico serológico de la prueba de inmunoblot para el diagnóstico de echinococosis quística humana, usando antígeno hidatídico de caprino y de ovino.

\section{EL ESTUDIO}

Se realizó un estudio de prueba diagnóstica durante el año 2009 previa aprobación por el Comité de Ética del Instituto Nacional de Salud, en cuatro etapas diferenciadas: selección de sueros humanos para ser utilizados sueros problema y controles, preparación del antígeno hidatídico de ovino y de caprino, preparación de la técnica de inmunoblot y determinación de la eficiencia diagnóstica de la prueba. A continuación se describe cada una de estas etapas ${ }^{(5,9-13)}$.

\section{SUEROS HUMANOS}

Se seleccionó por conveniencia 135 sueros; de los cuales, 70 procedieron de pacientes con enfermedad hidatídica, confirmada por el hallazgo de protoescólices y membra- na en el estudio anatomopatológico de la pieza quirúrgica (prueba de referencia o gold standard); 20 sueros fueron de personas sin hidatidosis, provenientes de zonas no endémicas, con prueba radiográfica y ecográfica aparentemente normal; además, se usó 45 sueros procedentes de pacientes con otras enfermedades (cuatro sueros de pacientes con entamoebiosis, cuatro con himenolepiosis, cuatro con ascariosis, dos con trichuriosis, dos con giardiosis, uno con strongiloidiosis, ocho con cisticercosis, tres con toxoplasmosis, dos con brucelosis, dos con leptospirosis, uno con leishmaniosis, siete con fasciolosis y cinco con teniosis). A los pacientes con fasciolosis y cisticercosis se descartó la enfermedad hidatídica mediante radiografía de tórax y a los demás pacientes con otras enfermedades se les descartó la hidatidosis mediante la ausencia de sus síntomas clínicos y por la procedencia de zonas no endémicas. Las muestras fueron seleccionadas y obtenidas de la Seroteca del Laboratorio de Zoonosis Parasitaria del Instituto Nacional de Salud, la confirmación por cirugía y patología de los pacientes con hidatidosis, se realizó en los hospitales Edgardo Rebagliati Martins, Hospital Nacional Hipólito Unanue y el Hospital Nacional Dos de Mayo.

Los pacientes con hidatidosis procedieron de Lima (35), Junín (15), Huancavelica (6), Cerro de Pasco (6), Ayacucho (4), Cusco (1), Moquegua (1), Ancash (1) y Puno (1), las edades oscilaban entre 4 y 78 años. La ubicación de los quistes, fueron localizados en el hígado (47), en el pulmón (19), en hígado/pulmón (2), en hígado/ pulmón/bazo (1) y en cerebro (1).

Los sueros positivos a cisticercosis se confirmaron con inmunoblot, los de fasciolosis con Arco II y los de toxoplasmosis con IFI. Los sueros de pacientes con Taenia sp, con entamoebiosis, himenolepiosis, ascariosis, trichuriosis, giardiosis y estrongiloidiosis fueron confirmados por el hallazgo, mediante el método parasitológico en heces de al menos una de las formas evolutivas características; los sueros con leptospirosis fueron confirmados con la prueba de ELISA y con aglutinación, mientras que los positivos a Brucelosis se confirmaron mediante la prueba del 2 mercaptoetanol en placa y en tubo. Los sueros con leptospirosis y Brucelosis fueron incluidos para evitar alguna reacción cruzada y a la vez para indagar si no existe inmunógenos comunes entre estos agentes etiológicos y el antígeno hidatídico, que puedan reaccionar a la prueba de inmunoblot.

\section{PREPARACIÓN DEL ANTÍGENO HIDATÍDICO DE CAPRINO Y DE OVINO}

Obtención de los quistes hidatídicos de caprino y de ovino. Se colectó hígados y pulmones, con quistes hidatídicos fértiles, de caprinos y de ovinos sacrificados en el Camal de Yerbateros (Lima, Perú), entre enero y 
marzo de 2009. En el laboratorio, el líquido hidatídico fue extraído asépticamente con una jeringa y transferido a frascos estériles, para luego ser centrifugado a $5000 \mathrm{rpm}$ a $4{ }^{\circ} \mathrm{C}$ durante 30 minutos; el sobrenadante se conservó a $-20^{\circ} \mathrm{C}$ hasta el momento de su procesamiento mientras que el sedimento se observó al microscopio para confirmar la presencia de protoescólices que demuestren la fertilidad de los quistes de E. granulosus.

Diálisis y liofilización del líquido hidatídico. El líquido hidatídico se dializó usando una membrana (MWCO: $6000-8000$ peso molecular) por tres días a $4{ }^{\circ} \mathrm{C}$ contra agua destilada, la cual fue cambiada tres veces. El volumen de agua destilada empleada fue 100 veces mayor que el volumen de líquido hidatídico por dializar. Luego de dializado, el líquido hidatídico se liofilizó.

Cuantificación de proteínas del antígeno hidatídico. Los antígenos liofilizados de caprino y de ovino fueron resuspendidos separadamente con buffer Tris $\mathrm{HCL}$ a $\mathrm{pH}$ 7,5; se centrifugó a $14000 \mathrm{rpm}$ por una hora a $4{ }^{\circ} \mathrm{C}$ y el sobrenadante fue separado y usado como antígeno; la concentración de proteínas en el antígeno se midió con el método de Lowry y se conservó a $-20^{\circ} \mathrm{C}$ hasta su uso.

Control del antígeno hidatídico. Los antígenos hidatídicos de caprino y de ovino fueron evaluados mediante la prueba de inmunoelectroforesis usando doble difusión en gel de agarosa al 0,9\% confirmándose la presencia del arco $\mathrm{V}$ al enfrentarlo a un suero control positivo de referencia. A estos antígenos también se les analizó mediante la prueba de electroforesis en gel de poliacrilamida al $15 \%$ para confirmar y caracterizar los componentes proteicos según su peso molecular.

\section{TÉCNICA DE INMUNOBLOT}

La separación de las proteínas antígénicas de los antígenos en estudio se realizó siguiendo la metodología descrita por Sánchez et al. (11), se empleó un sistema discontinuo en el gel de separación y en el gel de empaquetamiento. El equipo usado fue de sistema vertical (Mini-Protean II Electroforesis cel, Bio-rad). Los pasos fundamentales fueron los siguientes:

Tratamiento de los antígenos. Los antígenos en estudio fueron diluidos, volumen a volumen, con una solución de tratamiento de muestra que contiene $0,5 \mathrm{M}$ Tris HCL, pH 6,8; 0,1 M de 2 mercaptoetanol, 0,02\% de dodecil sulfato de sodio (SDS), $10 \%$ de glicerol y $0,1 \%$ de azul de bromofenol. Luego esta mezcla fue sometida a baño María a $100^{\circ} \mathrm{C}$ por cinco minutos.

Separación electroforética. Se realizó en geles de $8 \times 7 \times 0,05 \mathrm{~cm}$ en una cámara vertical (Mini Protean), con una concentración de acrilamida del gel separador de $15 \%$ y del concentrador de $4 \%$. Los corridos se realizaron a 160 voltios. En cada corrido se incluyó el marcador de peso molecular (low - range, Biorad), que sirvió de referencia para calcular los pesos moleculares reales. Se buscó la concentración proteica antigénica ideal para cada antígeno hidatídico en estudio, que se realizó en geles de poliacrilamida por coloración de azul de comassie, mediante un perfil antigénico tomando las siguientes concentraciones protéicas: $1 \mu \mathrm{g} / \mathrm{mm} ; 1,3$ $\mu \mathrm{g} / \mathrm{mm} ; 1,6 \mu \mathrm{g} / \mathrm{mm} ; 2 \mu \mathrm{g} / \mathrm{mm} ; 2,3 \mu \mathrm{g} / \mathrm{mm} ; 2,6 \mu \mathrm{g} / \mathrm{mm}$; $3,0 \mu \mathrm{g} / \mathrm{mm}$. La concentración ideal fue seleccionada observando las bandas antigénicas más nítidas.

Transferencia electroforética. Los componentes corridos fueron transferidos a papel de nitrocelulosa, usando una célula de transferencia (Biorad). Los geles fueron brevemente lavados con buffer de transferencia (0,2M Tris- HCL, $20 \%$ de metanol y agua bidestilada). La transferencia se realizó a 55 voltios por 90 minutos a $4{ }^{\circ} \mathrm{C}$. Las membranas de nitrocelulosa con las proteínas transferidas, fueron lavadas cuatro veces con PBS/tween$20(0,1 \mathrm{M} \mathrm{NaCL}, 0,05 \mathrm{M} \mathrm{Na} 2 \mathrm{PO} 4, \mathrm{pH} 7,2)$ con $0,3 \%$ tween 20) en agitación constante; seguidamente, se realizó el bloqueo de la zona no saturada por los antígenos, con PBS/tween-leche ( $5 \%$ de leche), por 30 minutos en agitación constante. Luego fueron cortadas en tiras de 3 $\mathrm{mm}$ de ancho en forma perpendicular al eje de migración de la electroforesis, luego se dejó secar y finalmente se los guardó a temperatura de entre 2 a $8^{\circ} \mathrm{C}$.

Detección inmunoenzimática. Las tiras de nitrocelulosa se incubaron en PBS/tween-20-leche con los sueros en estudio, a la dilución de 1/100. El volumen de la muestra diluida, por canal de la placa de incubación, fue de $1 \mathrm{~mL}$. Las tiras se incubaron a temperatura ambiente por una hora, luego se lavaron cinco veces con PBS/Tween-20 y, posteriormente, se incubaron en agitación constante por una hora con conjug ado (anti IgG ligada a una peroxidasa), a la dilución de 1/1000 en PBS/tween-20. Para visualizar las bandas antigénicas, las tiras fueron incubadas en solución de substrato (peroxido de hidrógeno $0,01 \%$ y la diaminobencidina a $0,5 \mathrm{mg} / \mathrm{mL}$ en PBS $\mathrm{pH}$ $7,2)$ por 5 a 10 minutos, hasta la aparición del color de las bandas. Las tiras se lavaron cinco veces con agua destilada para detener la reacción y eliminar el substrato. Luego se secó y se pegó en forma ordenada.

\section{INTERPRETACIÓN DE RESULTADOS}

Para el antígeno hidatídico de ovino el criterio de positividad para el diagnóstico de hidatidosis fue el reconocimiento de uno o más péptidos antigénicos de $\mathrm{Mr}$ entre 21 y 31 kDa por anticuerpos específicos presentes en el suero del paciente. 
Para el antígeno hidatídico de caprino el criterio de positividad se realizó de la siguiente manera: se escogió uno a mas péptidos que reaccionen con los sueros hidatídicos y a la vez que no reaccionen con los sueros no hidatídicos, siendo estas bandas entre 21 y 31 kDa.

\section{ANÁLISIS ESTADÍSTICO}

Los datos fueron digitados en Excel, y procesados con el programa Epidat v.3.1. Se calculó la sensibilidad, especificidad y valores predictivos con sus correspondientes intervalos de confianza al 95\%. Se evaluó la concordancia entre pruebas usando kappa.

\section{HALLAZGOS}

La concentración óptima del antígeno de líquido hidatídico de caprino y de ovino para la preparación de las tiras hidatídicas de electroinmunotransblot fue de $2,3 \mu \mathrm{g} / \mathrm{mm}$.

Las bandas observadas del antígeno hidatídico de caprino y de ovino fueron las mismas al ser evaluadas en geles de poliacrilamida y coloreadas con azul de comassie, estas fueron 12 y son las siguientes: 11, 14, $16,21,25,31,33,38,45,66,93$ y $98 \mathrm{KDa}$

Las bandas específicas para el criterio de positividad en la prueba de inmunoblot, al utilizar antígeno hidatídico de ovino y de caprino, se encuentran entre 21 y $31 \mathrm{kDa}$ $(21,25$ y $31 \mathrm{kDa})$. Fue suficiente que aparezca una banda en ese rango para determinar el resultado de la muestra como positivo.

Para la prueba de inmunoblot usando el antígeno hidatídico caprino (Tabla 1) se obtuvo una sensibilidad de $92,9 \%$ (IC95\%: 86,1-99,6\%), especificidad de 100\% (IC95\%: 99,2-100\%), valores predictivos positivos de 100\% (IC95\%: 99,2-100\%), y valores predictivos negativos de 92,9\% (IC95\%: 86,1-99,6\%), con un índice kappa de 0,93 (IC95\%: 0,86-0,99).

Los resultados obtenidos usando el antígeno hidatídico ovino (Tabla 1), muestran una sensibilidad de $91,4 \%$ (IC95\%: 84,2-98,7\%), una especificidad de 95,4\% (IC95\%: 89,5-100\%), valores predictivos positivos de $95,5 \%$ (IC95\%: 89,8-100\%), y valores predictivos negativos de 91,2\% (IC95\%: 83,7-98,7\%), y un índice kappa de 0,86 (IC95\%: 0,78-0,95).

Los resultados de validación diagnóstica entre los dos sueros hidatídicos no muestran diferencias significativas, además, observamos que sus intervalos de confianza se traslapan. No se encontró falsos positivos entre los pacientes sanos en ninguno de los dos sueros hidatídicos evaluados (ovino y caprino), pero sí se reporto
Tabla 1. Resultados del inmunoblot usando antígeno hidatídico de caprino y ovino con sueros hidatídicos y no hidatídicos.

\begin{tabular}{|c|c|c|c|c|c|}
\hline \multirow{2}{*}{ Sueros } & \multirow{2}{*}{$\begin{array}{c}\text { Total } \\
\mathbf{n}\end{array}$} & \multicolumn{2}{|c|}{$\begin{array}{c}\text { Inmunoblot } \\
\text { positivo }\end{array}$} & \multicolumn{2}{|c|}{$\begin{array}{l}\text { Inmunoblot } \\
\text { negativo }\end{array}$} \\
\hline & & Caprino & Ovino & Caprino & Ovino \\
\hline Hidatidosis & 70 & 65 & 64 & 5 & 6 \\
\hline Aparentemente sanos & 20 & 0 & 0 & 20 & 20 \\
\hline Cisticercosis & 8 & 0 & 0 & 8 & 8 \\
\hline Fasciolosis & 7 & 0 & 2 & 7 & 5 \\
\hline Teniósico & 5 & 0 & 0 & 5 & 5 \\
\hline Entamoebiosis & 4 & 0 & 0 & 4 & 4 \\
\hline Hymenolepiosis & 4 & 0 & 0 & 4 & 4 \\
\hline Ascariosis & 4 & 0 & 0 & 4 & 4 \\
\hline Toxoplasmosis & 3 & 0 & 1 & 3 & 2 \\
\hline Brucelosis & 2 & 0 & 0 & 2 & 2 \\
\hline Leptospirosis & 2 & 0 & 0 & 2 & 2 \\
\hline Trichuriosis & 2 & 0 & 0 & 2 & 2 \\
\hline Giardiosis & 2 & 0 & 0 & 2 & 2 \\
\hline Estrongiloidiosis & 1 & 0 & 0 & 1 & 1 \\
\hline Leishmaniosis & 1 & 0 & 0 & 1 & 1 \\
\hline Total & 135 & 65 & 64 & 70 & 68 \\
\hline
\end{tabular}

reacción cruzada en los sueros de toxoplasmosis (1/3) y fasciolosis (2/7) con el antígeno hidatídico de ovino.

La sensibilidad varió según la localización del quiste hidatídico, cuando hepático la sensibilidad fue de 95,7\% para ambos antígenos; pero cuando la localización fue pulmonar, la sensibilidad varió a $89,5 \%$ con antígeno caprino y $84,2 \%$ con antígeno ovino.

\section{DISCUSIÓN}

El líquido de quiste hidatídico es el más utilizado como fuente de antígeno para el inmunodiagnóstico de la echinococosis quística, sin embargo, éste es una mezcla compleja deantígenos del parásito y componentes séricos del hospedero. La presencia de estos contaminantes en el líquido hidatídico han limitado su utilización para el diagnóstico específico de E. granulosus. Dos de estos antígenos, inicialmente denominados antígeno 5 y antígeno B o 4 son inmunodominates en preparaciones antigénicas del parásito y tienen inmunorreactividad alta con sueros de pacientes hidatídicos ${ }^{(3)}$.

Una serie de antígenos fueron identificados y analizados con inmunoblot, en cuanto a especificidad, a partir de preparaciones de líquido hidatídico de diversos 
orígenes, con ello se verificó la existencia en el Perú de bandas con masas moleculares de 21 a 31 kDa con valor diagnóstico específico para la hidatidosis humana utilizando antígenos preparados a partir de líquido de quiste hidatídico de ovino y evaluados con sueros de pacientes procedentes también de Perú ${ }^{(6,14)}$.

En el presente trabajo se determinó 12 bandas antigénicas, cuyos pesos moleculares fueron, coincidentemente, las mismas, tanto para el antígeno hidatídico de caprino como para las de ovino, siendo estas las siguientes: 11, $14,16,21,25,31,33,38,45,66,93$ y $98 \mathrm{kDa}$, de las cuales las bandas de 21, 25 y 31 kDa fueron específicas para echinococosis quística.

La sensibilidad, la especificidad, el valor predictivo positivo y valor predictivo negativo de la prueba de inmunoblot, con antígeno hidatídico de caprino fue de 92,8; 100; 100 y $92,8 \%$ respectivamente; mientras que con antígeno de ovino fue de 91,$4 ; 95,3 ; 95,5$ y $91,1 \%$ respectivamente, siendo estos resultados dependientes de los principales factores que influyen en las respuestas del huésped a los antígenos del quiste hidatídico que lo constituyen, la cepa de parásitos, la inmunocompetencia del huésped, el órgano parasitado, la fertilidad del quiste, la viabilidad de las larvas y la integridad de la membrana germinativa ${ }^{(4)}$.

Sánchez ${ }^{(6)}$ en 1995, estandarizó el inmunoblot con antígeno del líquido hidatídico de ovino, concluyendo en el criterio de positividad a las bandas entre 21 y $31 \mathrm{kDa}$ con una sensibilidad de $95 \%$ y una especificidad de $100 \%$. Sin embargo, para el cálculo de estos parámetros sólo usaron 100 sueros, de los cuales 50 fueron hidatídicos y los otros 50 fueron no hidatídicos. Posteriormente, Gómez ${ }^{(7)}$ en el 2004, también trabajando con antígeno hidatídico de ovino pero sólo con 80 sueros, de las cuales 40 fueron hidatídicos y 40 no hidatídicos, obtuvo una sensibilidad de $95 \%$ y una especificidad de $95 \%$. Estos valores son similares a nuestros resultados con antígeno ovino (los intervalos de confianza de estas pruebas se superponen)

Variaciones no significativas como las encontradas, pueden deberse a la cantidad y procedencia de los sueros en estudio, puesto que este valor varía en relación a la calidad y cantidad de anticuerpos formados por el huésped en respuesta a los antígenos del quiste hidatídico. La calidad está determinada por la capacidad inmunogénica de los antígenos parasitarios que estimulen al sistema inmune del huésped mientras que la concentración de anticuerpos depende de la intensidad del estímulo, ambos parámetros varían en las diferentes poblaciones del huésped (7).

Al comparar la sensibilidad de la prueba de inmunoblot, obtenida con el antígeno hidatídico de caprino (92,8\%) y la obtenida con el antígeno hidatídico de ovino $(91,4 \%)$ y tomando como criterio de positividad a las bandas entre 21 y $31 \mathrm{KDa}$, se demuestra que el antígeno hidatídico de caprino presenta mayor sensibilidad (no significativa) que el antígeno de ovino. Asimismo, al comparar la especificidad se obtuvo con el antígeno hidatídico de caprino $100 \%$ y con el antígeno hidatídico de ovino $95,3 \%$, demostrándo también una mejor especificidad al usar el antígeno de caprino, en tal sentido se concluye que el usar el antígeno hidatídico de caprino puede dar un mejor valor diagnóstico que el ovino.

En cinco de los sueros hidatídicos no se detectó anticuerpos con a ambas pruebas, podría deberse a que estos pacientes tenían un quiste único de tamaño menor a los cuatro $\mathrm{cm}$ de diámetro, además, tres de estos estaban calcificados y los otros dos eran quistes hialinos, en los cuales no hay salida de inmunógenos del parásito o es muy escasa. Se ha demostrado que la respuesta inmune del huésped está relacionada con la integridad de la capa germinal de la larva, la cual impide la salida del líquido hidatídico u otros productos parasitarios como inmunógenos, que estimulan al sistema inmune; de allí que los pacientes con este tipo de quistes calcificados o hialinos muestran serología negativa ${ }^{(4)}$.

EI E. granulosus se caracteriza por presentar numerosas variantes genéticas que se denominan cepas, las que difieren en características morfológicas y biológicas con importancia actual y potencial para la epidemiología y el control de la enfermedad. En el mundo, el análisis de ADN permitió categorizar a las variantes de $E$. granulosus en nueve grupos genotípicamente diferentes (G1-9), de los cuales en Argentina se han aislado cinco: las cepas oveja común (genotipo G1), oveja de Tasmania (genotipo G2), vaca (genotipo G5), camello genotipo (G6) y cerdo (genotipo G7) ${ }^{(15)}$.

Con relación al suero hidatídico que reaccionó con el antígeno de caprino y no con el antígeno de ovino, podría explicarse por la variabilidad genética de las cepas de $E$. granulosus, pues a la fecha no hemos encontrado estudios que precisen el tipo de cepa de $E$. granulosus que se encuentra circulando en los diferentes hospederos intermediarios en el Perú. Sin embargo, el resultado es alentador, ya que utilizando antígeno hidatídico de caprino, se obtiene menos falsos negativos que con el antígeno hidatídico de ovino, pues esto conlleva a un mejor diagnóstico serológico de la echinococosis quística humana ${ }^{(9)}$.

Todos los sueros no hidatídicos al ser enfrentados al antígeno hidatídico de caprino, no presentaron reacción cruzada. Ello demuestra que las cepas procedentes de este hospedero intermediario, tienen inmunógenos de reconocimiento específico a anticuerpos hidatídicos ${ }^{(8,15)}$. 
La reacción cruzada observada con el antígeno hidatídico de ovino, en dos sueros de pacientes con fasciolosis y uno con toxoplasmosis, nos revela la presencia de antígenos comunes o proteínas diferentes con los mismos determinantes antigénicos entre estas tres parasitosis.

La diferencia en la sensibilidad de los antígenos según la localización del quiste, podría explicarse porque la localización pulmonar puede tener menores posibilidades de microfisuras en la pared del quiste, por lo que estos quistes son preponderantemente negativos a las pruebas serológicas usuales, a diferencia de los de localización hepática ${ }^{(16)}$.

El índice de kappa obtenido para ambas pruebas fue superior a 0,8 lo que lo califica como pruebas que tienen muy buena concordancia, en este caso con el estudio anatomopatológico ${ }^{(12)}$. Además, la alta cantidad de sueros usados nos proporciona un resultado más robusto que estudios previos.

Los resultados usando ambos antígenos fueron comparables. Las diferencias que se dieron son muy pequeñas y no son estadísticamente significativas, en tal sentido se recomienda usar cualquiera de los dos antígenos (ovino y caprino) para el diagnóstico serológico confirmatorio de la echinococosis quística humana.

\section{AGRADECIMIENTOS}

A Silvia Herrera por su apoyo en las facilidades para la recolección de antígenos, a William Quispe por el apoyo en la confirmación de algunos sueros hidatídicos, a Nishon Rojas por su apoyo en la preparación de algunos buffers y, a Elizabeth Sánchez por la transferencia de la metodología del inmunoblot.

\section{Fuente de Financiamiento}

Instituto Nacional de Salud.

\section{Conflictos de Interés}

Los autores declaran no tener conflictos de interés en la publicación de este artículo.

\section{REFERENCIAS BIBLIOGRÁFICAS}

1. Moro P, Schantz PM. Echinococcosis: a review. Int J Infect Dis. 2009; 13(2): 125-33.

2. Pérez C. Proyecto de control de hidatidosis en el Perú por vigilancia epidemiológica. [Tesis doctoral]. Lima: Facultad de Medicina, Universidad Nacional Mayor de San Marcos; 2007.

3. Gavidia CM, Gonzalez AE, Zhang W, McManus DP, Lopera L, Ninaquispe B, et al. Diagnosis of cystic echinococcosis, central Peruvian Highlands. Emerg Infect Dis. 2008; 14(2) 260-66.
4. Lorca M, Escalante H, García A, Denegri M, Sierra P, Silva M. Estandarización y evaluación de una técnica de ELISA para el diagnóstico de la hidatidosis humana. Parasitol Día. 1991; 15(3/4): 74-78.

5. Sánchez E, Náquira C, Gutiérrez S, Ayala E, Medina S. Manual de procedimientos técnicos para el diagnóstico serológico de la hidatidosis humana. Lima: Instituto Nacional de Salud; 1997. Serie de normas técnicas № 22.

6. Sánchez E. Determinaçao de antígenos relevantes de la forma larval do Echinoccocus granulosus: Padronizacao e aplicaçao do inmunoblot no diagnóstico de hidatidose humana. [Tese de maetria]. Rio de Janeiro: Instituto Oswaldo CruzFlocruz; 1995.

7. Gómez JC. Valor diagnóstico de inmunoblot con líquido hidatídico humano, frente a antígeno ovino y bovino. Rev Mex Patol Clin. 2004; 51(2): 75-89.

8. Verástegui M, Moro $\mathbf{P}$, Guevara A, Rodríguez T, Miranda E, Gilman RH. Enzyme-linked immunoelectrotransfer blot test for diagnosis of human hydatid disease. J Clin Mricrobiol. 1992; 30(6): 1554-67.

9. Miranda E, Sanchez E, Naquira C, Somocurcio J, Ayala E, Miranda G. Evaluación de una prueba de aglutinación de látex para el diagnóstico serológico de la equinococosis quística. Rev Peru Med Exp Salud Publica. 2009; 26(2): 198-202.

10. Fuentes F, Incio N, Levano J, Torres Y. Caracterización y optimización del antígeno del líquido hidatídico de ovino y su aplicación en la prueba de látex. Rev Peru Med Exp Salud Publica. 2009; 26(4): 473-77.

11. Sánchez E, Naquira C, Vega ES. Manual de procedimientos para el diagnóstico serológico de las zoonosis parasitarias. Lima: Instituto Nacional de Salud; 2002.

12. Organización Panamericana de la Salud. Manual de procedimientos de control de calidad para los laboratorios de serología de los bancos de sangre. Washington DC: OPS; 1994.

13. Tsang VC, Peralta JM, Simons AR. Enzyme-linked immunoelectrotransfer blot techniques (EITB) for studying the specificities of antigens and antibodies separated by gel electrophoresis. Methods Enzymol. 1983; 92: 377-91.

14. Sánchez E, Cáceres $O$, Náquira $C$. Aislamiento y purificación de una fracción antigénica de 21 a 31 kda de líquido de quiste hidatídico de Echinococcus granulosus. Lima: Instituto Nacional de Salud; 2004.

15. Virginio VG, Hernandez A, Rott MB, Monteiro KM, Zandonai $\mathbf{A F}$, Nieto $\mathbf{A}$, et al. $\mathrm{A}$ set or recombinant antigens from Echinococcus granulosus with potential for use in the immunodiagnosis of human cystic hydatid disease. Clin Exp Immunol. 2003; 132(2): 309-15.

16. Larrieu E, Frider B, Del Carpio M, Salvitti JC, Mercapide C, Pereyra R, et al. Portadores asintomáticos de hidatidosis: epidemiologia, diagnóstico y tratamiento. Rev Panam Salud Publica. 2000; 8(4): 250-56.

Correspondencia: Blgo. Eduardo Miranda Ulloa

Dirección: Cápac Yupanqui 1400, Lima11, Perú.

Teléfono: (511) 617-6200

Correo electrónico: emiranda@ins.gob.pe 